\title{
Economics
}

2021; 10(3): 87-93

$\mathrm{http}: / / w w w . s c i e n c e p u b l i s h i n g g r o u p . c o m / \mathrm{j} / \mathrm{eco}$

doi: $10.11648 /$ j.eco.20211003.13

ISSN: 2376-659X (Print); ISSN: 2376-6603 (Online)

\section{The Role of Inclusive Finance in the Quest for Inclusive Growth}

\author{
Israël Sawadogo, Ndiack Fall \\ Department of Economics and Management, Cheikh Anta Diop University (UCAD), Dakar, Senegal \\ Email address: \\ sawadisrael@gmail.com (I. Sawadogo),ndiackfall@gmail.com (N. Fall)
}

\section{To cite this article:}

Israël Sawadogo, Ndiack Fall. The Role of Inclusive Finance in the Quest for Inclusive Growth. Economics. Vol. 10, No. 3, 2021 , pp. 87-93. doi: 10.11648/j.eco.20211003.13

Received: May 25, 2021; Accepted: June 28, 2021; Published: August 24, 2021

\begin{abstract}
This paper aims to assess the effect of inclusive finance on the level of inclusive growth in West African Economic and Monetary Union (WAEMU) countries. For that purpose, a synthetic indicator for inclusive growth is elaborated. Then, this indicator is used as an endogenous variable in a dynamic panel model including the main factors of the financial system as exogenous. About financial variables used in this paper, inclusive finance is apprehended by rate of use of banking services and microfinance penetration rate. In addition, the different types of bank interest rates are used in this analysis to show their effects on the evolution of inclusive growth. Results showed a positive and significant effect of the development of banking services on inclusion of growth in the (WAEMU) countries. However, the penetration rate of microfinance services did not show a significant effect on the evolution of inclusive growth of these economies. The levels of interest rates granted by banks according to the type of beneficiary (loans to individuals) or the item of use (equipment loans and consumer loans) negatively influence inclusive growth in the WAEMU countries. Overall, these results indicate that actions to promote the use of banking services would be beneficial to the process of inclusion of growth for WAEMU countries. With regard to microfinance services, actions must first focus on improving the efficiency of current microfinance services and then proceed to the popularization of these services.
\end{abstract}

Keywords: Inclusive Finance, Inclusive Growth, Penetration Rate, Loans, Interest Rates, Dynamic Panel

\section{Introduction}

In African economies, several challenges remain in the implementation of monetary policy, in particular the catching up of the delay in economic and social development. Achieving inclusive growth through the reduction of poverty and the depth of inequalities appears in most of action plans of economic development policies and programs. Inclusive growth illustrates a process of economic growth that creates significant socio-economic opportunities and ensures fair access to these opportunities. In addition, the quest for resilient and inclusive growth remains at the heart of the defined objectives. For example, the main mission of African Development Bank (AfDB) is to reduce poverty in its regional member countries by contributing to their sustainable economic development and social progress.

Similarly, promoting inclusive growth through financial inclusion is a topical issue for the Central Bank of West African States. Indeed, in April 2018, a financial inclusion department was instigated by the Governor of the Central Bank of West African States with the aim of federating all initiatives devoted to financial inclusion, with a view to contributing to the intensification of growth and the balanced sharing of its outcomes. The intervention of the monetary authorities in the quest for inclusive growth of West African Economic and Monetary Union (WAEMU) countries is mainly motivated by the repercussions that monetary and financial policies would have on the process of distribution and redistribution of wealth in the economy. In addition, in the implementation of policies to optimize the opportunities created by growth at the national level, the implementation of accompanying monetary policies would condition the achievement of the defined objectives in a sustainable way.

Otherwise, certain conditions presented by the financial system at the national level are related to the effectiveness of the implementation of such policies. Because financial intermediation is an important tool in the process of redistribution of wealth and households' inter-temporal 
decisions. However, although several challenges are launched in the direction of improving the level of inclusive growth through the development of the financial system, conclusions remain weaker with regard to the assessment of financial policies to this effect. These various points thus justify the need for an in-depth analysis of the link between financial factors and inclusive growth.

The objective of this paper is to assess the effect of inclusive finance in the quest for inclusive growth in WAEMU countries. To carry out this analysis, it is necessary to define a first hypothesis of the effective importance of financial inclusion in the process of inclusion of growth. The second hypothesis is the positive impact of the performance of financial products on the pace of inclusive growth.

\section{Literature Review}

\subsection{Concept of Inclusive Growth}

Since 1950, several economists have been interested in the link between the level of growth and the level of development for a given economy. Among the concepts developed in this direction stands out the hypothesis of the inverted $U$ relationship formulated by Kuznets [10]. This hypothesis states that economic growth follows a first stage of a gap in inequalities but at a second stage of a reduction of these inequalities. Over the past two decades, the need to characterize the notion of inclusive growth has given rise to several waves of definitions that are the subject of debates in development economics. A first wave of definitions, based on the distribution of income in the population, analyzes inclusive growth broadly as an economic growth benefiting all layers of society, including the poor, near-poor, middle income groups, and even the rich (Anand et al. [2], Klasen [9] or McKinley [11]). However, these previous analyzes of inclusive growth only focus on distributed income as well as the other components of economic growth. It is in this context that a new wave will emerge, trying to introduce elements other than income into the analysis of inclusive growth while viewing it as a process. Inclusive growth was thus defined as economic growth creating economic opportunities accessible to all and in particular to the poor, to the extent possible (Ifzal \& Hyun [7]).

\subsection{Empirical Review About the Financial System and Economic Growth}

Recent developments in the literature on the relationship between financial inclusion and economic growth have been marked by the crucial role of financial inclusion in sustainable development, poverty reduction, and fostering shared prosperity.

Pradhan et al. [14] presented an empirical result of the relationship between the penetration of the insurance market, which is one of the factors of financial inclusion, and economic growth. Their analyses examined the causal interaction of insurance market penetration, broad money, market capitalization, and economic growth with a focus on the Association of Nations Regional Forum of the Association of Southeast Asian Nations. The results revealed the existence of a short-term two-way causality between the insurance market and economic growth.

Naceur and Ghazouani [12] analyzed the relationship between financial development and economic growth for 11 countries in the MENA region (Middle East and North Africa). Their work concluded that the underdeveloped financial systems in this region hinder economic growth.

Williams et al. [15] empirically investigated the role of financial inclusion in the process of economic growth and poverty reduction in a developing economy using panel data from 2006 to 2015 in a framework linear logarithmic model specification. The results of the study show that the number of active Automated Teller Machines (ATMs), bank branches and public expenditure selected in three African countries were the strongest predictors of financial inclusion on an improvement in the level of economic growth and of poverty reduction in a developing economy.

Kim et al. [8] examined the relationship between financial inclusion and economic growth in Organization of Islamic Cooperation (OIC) countries with panel data for 55 countries. Based on the results of dynamic panel estimates, they found that financial inclusion has a positive effect on economic growth. The analysis of IFRs derived from the panel Vector Autoregression (VAR) model also shows that financial inclusion has positive effects on economic growth and that the two have mutual causalities between them based on the Granger panel causality tests.

\section{Method}

\subsection{Construction of an Inclusive Growth Indicator (IGI)}

The construction of the inclusive growth indicator (IGI) in this study is based on the approach of Multiple Factorial Analysis. The multidimensional approach has been adopted by some authors as Anago and Houngbene [1], Fall et al. [6] or Ncube [13] who have looked at the impact and quality of economic growth.

Functional form of the index

There are two levels of aggregation in the construction of the composite indicator: the first concerns the variables at the level of each dimension and the second is the aggregation of the strategic axes

$$
I G I=\left[\frac{1}{\sum_{k=1}^{m} \gamma_{k}} \sum_{k=1}^{m} \gamma_{k} I_{k}^{\alpha}\right]^{1 / \alpha}
$$

Where $m$ is the number of dimensions retained for the index. The $\gamma_{k}$ is the total weight of the dimension in the constitution of the global index and are obtained at the end of the multiple fact analysis (MFA) carried out. This is the total score of the indicators summarizing the dimension $\mathrm{k}$. $I_{k}$ is the sub-indicator associated with dimension $\mathrm{k}$ and is obtained from principal component analysis (PCA) carried out on the latter. 


$$
I_{k}=\sum_{i=1}^{n} S_{i} V_{i}
$$

Where $S_{i}$ is the score of the $\mathrm{i}^{\text {th }}$ variable on the factorial axis considered and $V_{i}$ its value.
Variables used for the construction of the indicator

Inclusive growth indicator in this study is constructed from 17 variables grouped in three dimensions, namely the economic dimension, the social dimension and the standard of living.

Table 1. Variables used for the construction of inclusive growth indicator (IGI).

\begin{tabular}{|c|c|c|c|}
\hline Variable & Contribution to IGI & Variable & Contribution to IGI \\
\hline economic dimension & & Life expectancy at birth & + \\
\hline GDP growth rate & + & Mortality rate, infant & - \\
\hline Unemployment rate & - & Maternal mortality ratio & - \\
\hline GDP per capita growth rate & + & Incidence of tuberculosis & - \\
\hline Household final consumption expenditure per capita growth & + & standard of living dimension & \\
\hline GDP per person employed & + & Individuals using the Internet (\% of population) & + \\
\hline social dimension & & Mobile cellular subscriptions (per 100 people) & + \\
\hline Government expenditure on education ( $\%$ of GDP) & + & Access to electricity (\% of population) & + \\
\hline net school enrollment rate & + & Access to an improved water ( $\%$ of population) & + \\
\hline Health expenditure, total ( $\%$ of GDP) & + & Access to improved sanitation (\% of population) & + \\
\hline Sources: authors & & & \\
\hline
\end{tabular}

\subsection{Estimation}

\subsubsection{Analytical Framework}

Two main models are implemented in this study with same variable of interest which is the indicator of inclusive growth. The first aims to explain the indicator of inclusive growth by the variables measuring the level of inclusion and the different types of interest rates depending on the type of credit beneficiary. The second includes the interest rates on the financial market according to different channels of use of the credits.

The dynamic model is presented as follows:

$$
I G I_{i t}=\alpha_{0}+\alpha I G I_{i t-1}+\sum_{j=1}^{K} \beta_{j} x_{j, i t}+\mu_{i}+\varepsilon_{i t}
$$

With $\alpha_{0}$ the constant, $\alpha$ the effect of the IGI lags on its present value, $\beta_{j}$ the coefficient associated with the explanatory variable $x_{j}, \mu_{i}$ represents individual effect and $\varepsilon_{i t}$ the residual.

In the context of this study, estimations are made using the method of Blundell and Bond [5] instead of Arellano and Bond [3] and Arellano and Bover [4]. The validation of the model of Blundell and Bond [5] is made under three main assumptions. First, residuals have an autocorrelation of order 1. Second, they should not have an autocorrelation of order 2 or higher. The third condition designates the validity of the instruments used in the model.

\subsubsection{Variables and Data}

The variables used in the analysis of financial inclusion are the rate of use of banking services and the rate of penetration of microfinance services. The rate of use of banking services is determined by the proportion of users of banking services, in the adult population. The other financial variables used in the first model are interest rates attributed to loans granted respectively to individuals, sole proprietorships, private enterprises and rural cooperatives and groups. For a second model, the reference will be made to the interest rates according to the expected use of the credit (consumption, equipment and housing). The main source of monetary and financial data is Central Bank database (July 2019 version).

In terms of timeframe, the analysis is carried out over 10 years (2006 to 2015) and this restriction is due to the limitation of data on financial inclusion before 2006. Data thus defined present a balanced panel structure of 8 countries described over 10 years.

\section{Results and Implications}

The use of banking services positively and significantly affects the indicator of inclusion of economic growth. In fact, the improvement in access to banking services by $1 \%$ in period t-1 results in an increase of 0.031 in the level of inclusion of growth in period t. Literally, the rate of use of banking services measures access to the various financial services offered by commercial banks. These services include, in particular, the availability of liquidity, securing of financial assets, savings, access to bank loans, etc. Inclusive growth indicator measures the transmission between the economic growth caused in a given area and the equity in access to the opportunities provided by this growth. The link between these two economic factors would therefore appear in terms of access to the opportunities created by economic growth. At a level of in-depth economic analysis, promoting some quality banking services, accessible to different economic agents, helps to improve the financial atmosphere, so that a first group of agents are able to identify and make available an excess funding in favor of a second group of agents in need of funding.

One of the channels used to influence the financial behavior of small businesses is microfinance. Logically, a cleaning up of the micro-financial environment should play a capital role in the contribution of these institutional units 
to the economic development of a given area as well as to the improvement of the conditions of individuals. this role does not appear significant in this analysis carried out on the West African Monetary Union in 2006 and 2015. Indeed, the rate of penetration relating to microfinance services does not significantly influence the level of inclusive growth (Table 2).

The previous results are those obtained in models 1 where bank interest rates are introduced into the analysis according to the type of credit beneficiary. These results remain valid at the level of model 2 incorporating in the analysis bank interest rates according to the use made of credit.

Table 2. Estimation of the relationship between inclusive growth and the financial atmosphere indicators (model 1).

\begin{tabular}{|c|c|c|c|c|}
\hline \multirow{2}{*}{$\begin{array}{l}\text { Number of observations: } 72 \\
\text { Global significance test (Wald test) }\end{array}$} & \multicolumn{4}{|c|}{ Number of groups: 8} \\
\hline & \multicolumn{2}{|l|}{ Statistic: $\mathbf{5 3 8 . 9 1}$} & \multicolumn{2}{|c|}{$p$ value $(5 \%): 0.000$} \\
\hline Dependent variable: IGI (t) & Coefficient & p value $(5 \%)$ & \multicolumn{2}{|c|}{ Confidence interval $(95 \%)$} \\
\hline IGI (t-1) & $0.517 * * *$ & 0.000 & 0.271 & 0.762 \\
\hline Rate of use of banking services (t-1) & $0.031 *$ & 0.023 & 0.004 & 0.057 \\
\hline Microfinance penetration rate $(\mathrm{t}-1)$ & 0.019 & 0.555 & -0.045 & 0.083 \\
\hline \multicolumn{5}{|c|}{ Bank interest rate according to the credit recipient } \\
\hline Loans to individuals $(\mathrm{t}-1)$ & $-0.109 *$ & 0.013 & -0.195 & -0.023 \\
\hline Loans to private companies $(\mathrm{t}-1)$ & -0.076 & 0.134 & -0.174 & 0.023 \\
\hline Loans to rural cooperatives $(\mathrm{t}-1)$ & -0.021 & 0.278 & -0.059 & 0.017 \\
\hline Constant & $2.320 * *$ & 0.005 & 0.685 & 3.954 \\
\hline \multicolumn{5}{|c|}{ Dynamic panel model validation test (Ho: non autocorrelation) } \\
\hline Autocorrelation order & 1 & 2 & 3 & 4 \\
\hline Statistic & -2.3520 & -0.4330 & 1.1534 & -1.2615 \\
\hline $\mathrm{p}$ value $(5 \%)$ & 0.0187 & 0.6650 & 0.2487 & 0.2071 \\
\hline
\end{tabular}

Sources: authors.

With regard to factors related to bank credit, the analysis has been done in two directions. In a first level of analysis, with loans depending on the beneficiary, only the change in interest rates applied to bank credit granted to individuals significantly influences the level of inclusion of inclusive growth. An increase in the interest rate applied to bank credit granted to individuals in a period $\mathrm{t}-1$ causes a decrease in the inclusion of growth indicator evaluated at -0.109 (Table 2).

Tables 3. Estimation of the relationship between inclusive growth and financial atmosphere indicators (model 2).

\begin{tabular}{|c|c|c|c|c|}
\hline \multirow{2}{*}{$\begin{array}{l}\text { Number of observations: } 72 \\
\text { Global significance test (Wald test) }\end{array}$} & \multicolumn{4}{|c|}{ Number of groups: 8} \\
\hline & Statistic: 1900.26 & \multirow{3}{*}{$\frac{\text { p value }}{0,007}$} & \multicolumn{2}{|c|}{ p value: 0} \\
\hline \multirow{2}{*}{$\begin{array}{l}\text { Dependent variable: IGI (t) } \\
\text { IGI (t-1) }\end{array}$} & \multirow{2}{*}{$\begin{array}{l}\text { Coefficient } \\
0,530 * *\end{array}$} & & \multicolumn{2}{|c|}{ Confidence interval (95\%) } \\
\hline & & & 0,142 & 0,918 \\
\hline Rate of use of banking services (t-1) & $0,035 *$ & 0,025 & 0,004 & 0,065 \\
\hline Microfinance penetration rate $(\mathrm{t}-1)$ & $-0,001$ & 0,967 & $-0,047$ & 0,045 \\
\hline \multicolumn{5}{|c|}{ Bank interest rates according to the use of credit } \\
\hline Equipment credit (t) & $-0,117^{*}$ & 0,050 & $-0,234$ & 0,000 \\
\hline Consumer credit (t-1) & $-0,080 * *$ & 0,004 & $-0,135$ & $-0,026$ \\
\hline Constant & 2,306 & 0,133 & $-0,705$ & 5,317 \\
\hline \multicolumn{5}{|c|}{ Dynamic panel model validation test (Ho: non autocorrelation) } \\
\hline Autocorrelation order & 1 & 2 & 3 & 4 \\
\hline Statistic & $-2,299$ & 0,023 & 1,137 & $-0,996$ \\
\hline $\mathrm{p}$ value $(5 \%)$ & 0,022 & 0,982 & 0,256 & 0,319 \\
\hline
\end{tabular}

Sources: authors.

In summary, the findings on the links between financial inclusion and inclusive growth can be subdivided into two parts. The first component concerns the positive contribution of the rate of use of banking services to the creation of wealth as well as the improvement of the level of equity in access to the opportunities created at the end of this process. Several channels are likely to explain this link.

First, financial intermediation is one of the essential elements for the primary and secondary distribution of income obtained from the production process of goods and services. This intermediation allows households to suspend their inter-temporal planning behavior for consumer spending in a formal and reliable framework that such a financial system would offer.

Second, inclusive finance offers vulnerable populations the possibility of accessing quality financial services useful for the economic activities they carry out, especially those of informal production units and small businesses. Access to such services guarantees this category of economic agents an effective contribution to economic growth and an improvement in their living conditions through the income acquired for this purpose. However, analyzes carried out within the framework of this work do not seem to corroborate this assertion in WAEMU countries, given the negligible effect of microfinance 
penetration in improving the level of inclusive growth.

\section{Conclusion}

Faced with the need to analyze the behavior of the wealth creation process in WAEMU countries according to the evolution of other economic factors, this study sets itself the objective of determining the role played by inclusive finance. To achieve this objective, this work has contributed to computing a synthetic indicator illustrating inclusive growth which will then be used as an endogenous variable in a dynamic panel model integrating the main factors of the financial system as exogenous.

Results indicate to financial institutions cooperating with the WAEMU economies that actions to promote the use of banking services with fewer geographic gaps would be beneficial to the process of inclusion of growth. With regard to microfinance services, actions must first focus on improving the efficiency of current services and then proceed to the popularization of these services. The effect of different types of interest rates provide valuable information on the importance of conditioning this financial factor in the implementation of monetary policies aimed at reducing inequalities in access to opportunities created by growth.

\section{Appendix}

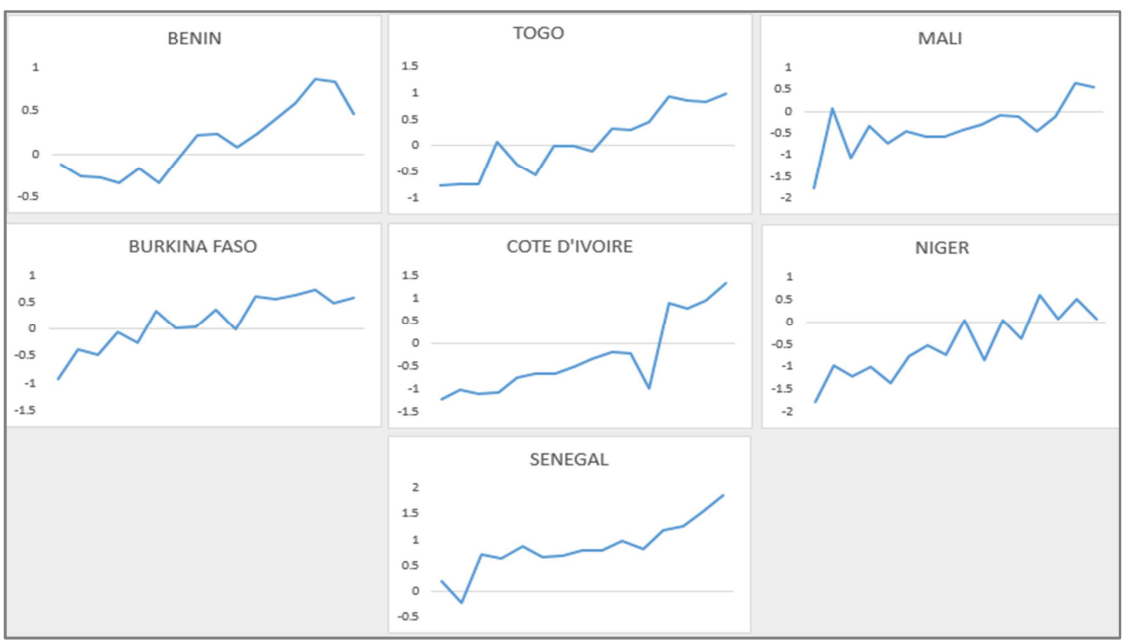

Sources: authors.

Figure 1. Evolution of the Inclusive Growth Indicator.

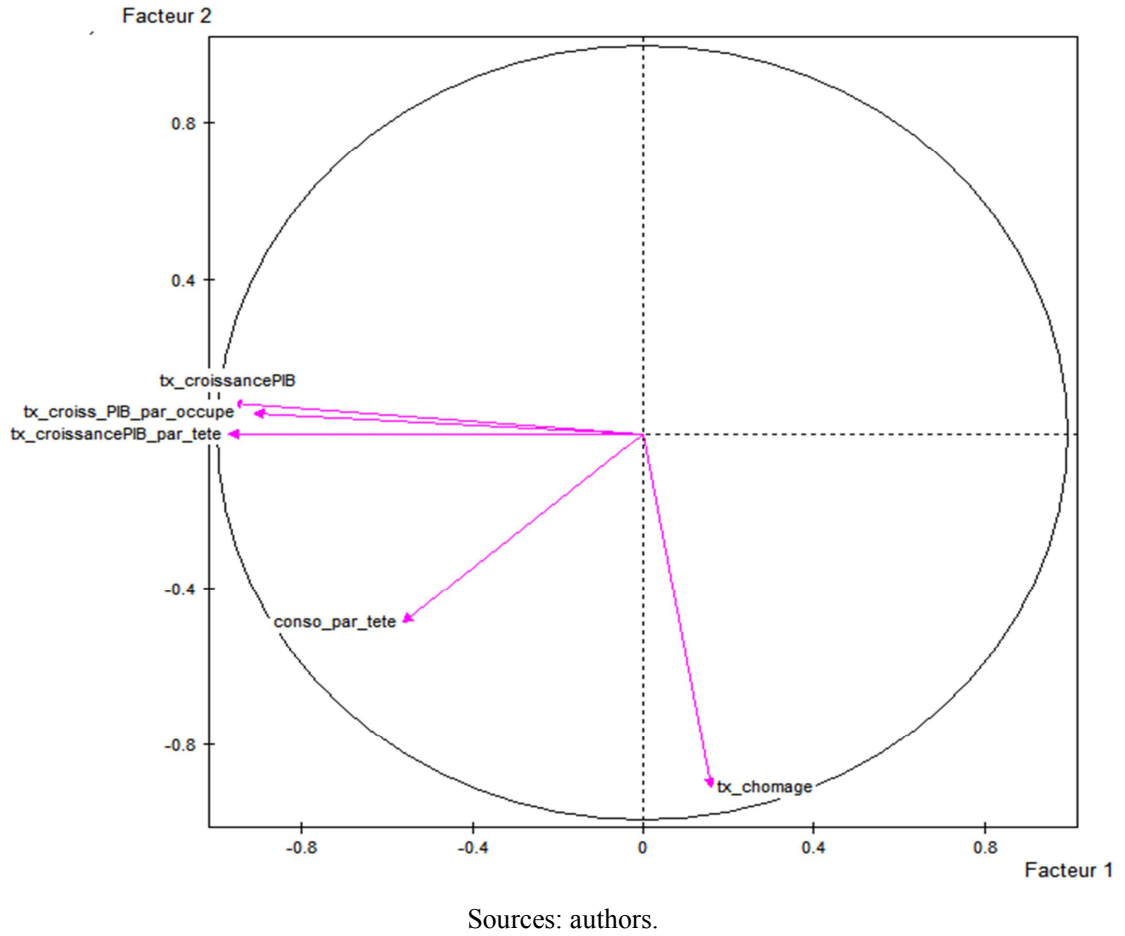

Figure 2. Factor analysis of the economic dimension of the indicator. 
Facteur 2

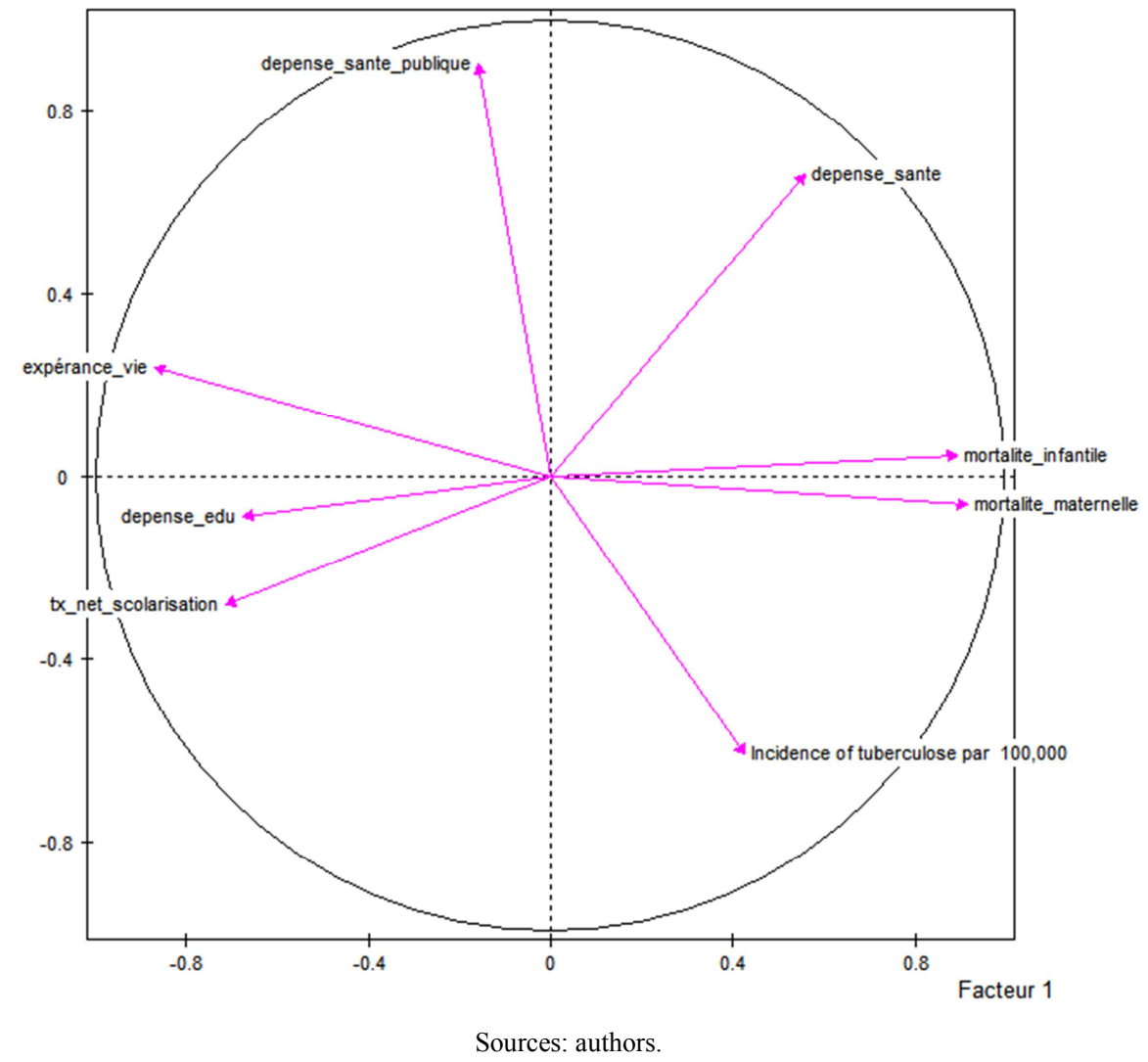

Figure 3. Factor analysis of the social dimension of the indicator.

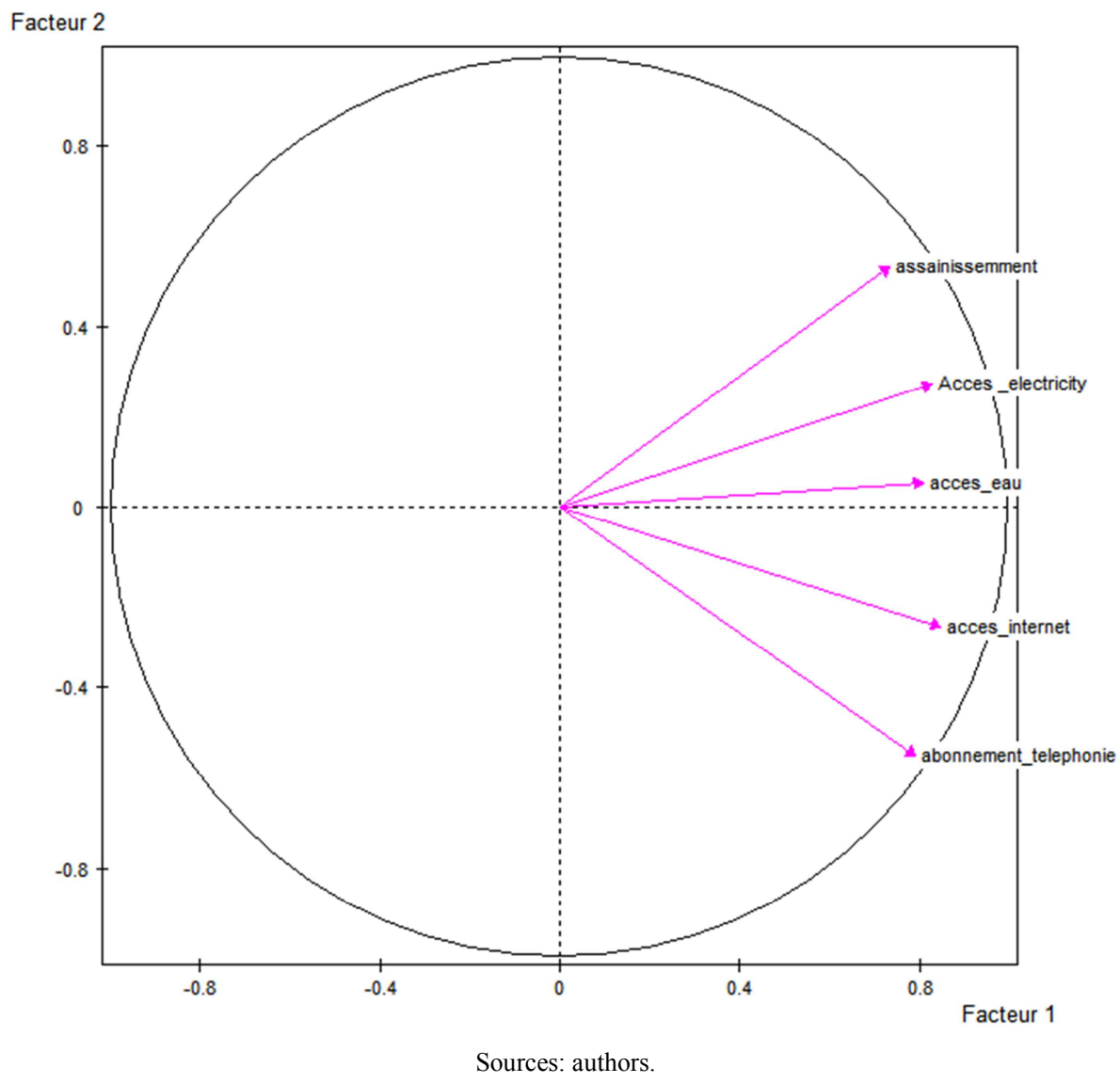

Figure 4. Factor analysis of the standard of living dimension of the indicator. 


\section{References}

[1] Anago, S. S., \& Houngbeme, J. D. (2015). construction of a synthetic indicator of inclusive growth. Economic and Financial Policy Analysis Review, Volume 1, Numero 1, August, pp $69-105$.

[2] Anand, R., Mishra, S., \& Peiris, S. (2013). Inclusive Growth: Measurement and Determinants. IMF Working Paper.

[3] Arellano, M., \& Bond, S. (1991). Some tests of specification for panel data: Monte Carlo evidence and an applicationto employment equations. Review of Economic Studies 58: 277297.

[4] Arellano, M., \& Bover, O. (1995). Another look at the instrumental variable estimation of error-components models. Journal of Econometrics 68: 29-51.

[5] Blundell, R., \& Bond, S. (1998). Initial conditions and moment restrictions in dynamic panel data models. Journal of Econometrics 87: 115-143.

[6] Fall, N., Sawadogo, I., \& Kanaza, H. (2021). International trade and inclusive growth in West African Economic and Monetary Union (WAEMU) countries. Estudio de Economia Aplicada. Volumen: 39-2 // ISSN: 1133-3197.

[7] Ifzal, A., \& Hyun, H. S. (2007). Defining and Measuring inclusive growth: application to the Philippines. ERD Working Paper No. 98, Mandaluyong City, Philippines.

[8] Kim, D., Yu, J., \& Hassan, M. K. (2017). Financial Inclusion and Economic Growth in OIC Countries. Research in
International Business and Finance. 43. 10.1016/j.ribaf.2017.07.178.

[9] Klasen, S. (2010). Measuring and Monitoring Inclusive Growth: Multiple Definitions, Open Questions, and Some Constructive Proposals. ADB Sustainable Development Working Paper Series $n^{\circ} 12$.

[10] Kuznets, S. (1955). Economic Growth and Income Inequality. The American Economic Review, pp. 1-28.

[11] McKinley, T. (2010). Inclusive Growth Criteria and Indicators: An Inclusive Growth Index for Diagnosis of Country Progress. ADB Sustainable Development Working Paper Series, No. 14. Mandaluyong City, Philippines, Asian Development Bank.

[12] Naceur, B. \& Ghazouani, S. (2007). Stock Markets, Banks, and Economic Growth: Empirical Evidence from the MENA Region. Research in International Business and Finance. 21. 297-315. 10.2139/ssrn.856386.

[13] Ncube, M. (2015). Inclusive Growth in Africa. The Oxford Handbook of Africa and Economics, Volume 1: Context and Concepts, DOI: 10.1093/oxfordhb/9780199687114.013.26.

[14] Pradhan, R. P., Arvin, M. B., Norman, N. R., Nair, M., \& Hall, J. H. (2016). Insurance penetration and economic growth nexus: cross-country evidence from ASEAN. Research in International Business and Finance 36, 447-458.

[15] Williams, H., Adegoke, A., \& Dare, A. (2017). Role of financial inclusion in economic growth and poverty reduction in a developing economy. Internal Journal of Research in Economics and Social Sciences. 7. 265-271. 